\title{
Preoperative determination of artificial chordae length: Wishful thinking?
}

\author{
Thilo Noack, MD, and Michael A. Borger, MD, PhD
}

\author{
From the Department of Cardiac Surgery, Heart Center, University of Leipzig, Leipzig, Germany. \\ Disclosures: Authors have nothing to disclose with regard to commercial support. \\ Received for publication Aug 6, 2017; accepted for publication Aug 8, 2017; available ahead of print Sept 8, 2017. \\ Address for reprints: Michael A. Borger, MD, PhD, Department of Cardiac Surgery, Leipzig Heart Center, \\ Struempellstrasse 39, 04289 Leipzig, Germany (E-mail: michael.borger@helios-kliniken.de). \\ J Thorac Cardiovasc Surg 2017;154:1632-3 \\ $0022-5223 / \$ 36.00$ \\ Copyright $(c) 2017$ by The American Association for Thoracic Surgery \\ http://dx.doi.org/10.1016/j.jtcvs.2017.08.006
}

Mitral valve repair using ring annuloplasty and artificial chordae implantation is the treatment of choice for patients with anterior leaflet prolapse. This technique allows surgeons to achieve the fundamental goal of restoring adequate leaflet coaptation and valve competency. The idea of chordae replacement with polytetrafluoroethylene (PTFE) was first introduced by Frater and colleagues ${ }^{1,2}$ and then rapidly integrated into the clinical realm by David and colleagues. ${ }^{3}$ The main difficulty of using artificial chordae is the determination of the length between the tip of the papillary muscle and the newly resupported leaflet edge. ${ }^{4}$ Further, the challenging sliding characteristics of PTFE during the tying process must be considered. These 2 issues explain why so many different techniques have been proposed for PTFE neochordal replacement, ${ }^{2,3,5-8}$ all of which are based on the reference point method first introduced by Carpentier. ${ }^{9}$ The reference point method can be applied during adjustments made at the leaflet level or at the ventricular level. ${ }^{4}$

Frater $^{10}$ summarized requirements for the consistent determination of artificial chordae length as follows: the length of new chordae must be such that the free edges of the opposing anterior and posterior leaflets are parallel when the chordae are placed under enough tension to hold them in a straight line, and chordal length can be determined preoperatively by echocardiography with a view that cuts through the prolapsing leaflet and the normal leaflet opposite it, and intraoperatively by gentle traction on the prolapsing and nonprolapsing opposing leaflets.

Both techniques-preoperative imaging-based and intraoperative direct determination of chordae lengthhave advantages and disadvantages. Intraoperative direct measurement allows the consideration of variations in subvalvular anatomy and tissue characteristics. The main disadvantage of this approach is the altered left ventricular geometry due to cardioplegic arrest of the heart. $^{11,12}$ Preoperative determination of artificial chordae length, which has mostly been performed echocardiographically to date, makes eminent sense. ${ }^{8,10-12}$ It allows determination of chordal length under

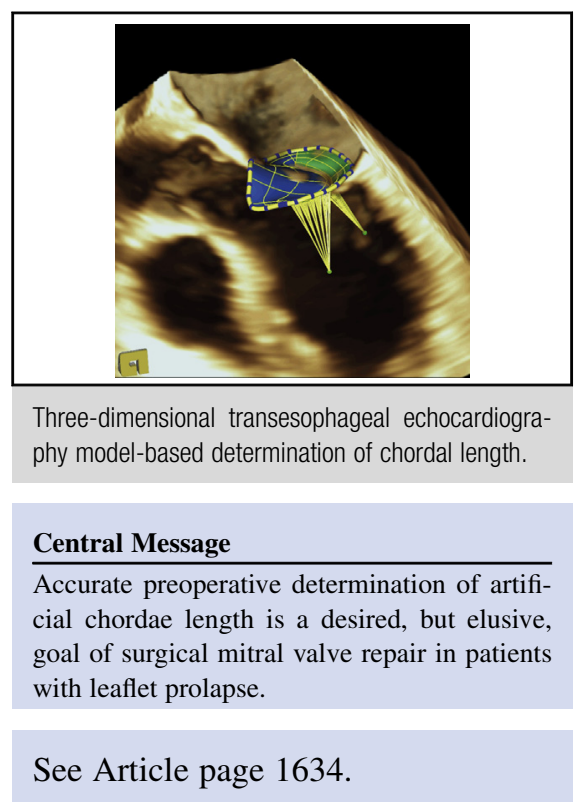

physiologic, full-loading conditions. However, preoperative image-based determination or prediction is technically challenging, time-consuming, and difficult to implement clinically. In fact, one could state that it is simply wishful thinking on the part of mitral surgeons. The large variation in normal subvalvular anatomy and mitral valve pathologies, combined with the limitations of current imaging techniques, explain the difficulties of preoperative determination. In particular, precise 3-dimensional patientspecific determination of the distance between the appropriate papillary muscle head and reference point leaflet edge has been problematic.

Despite the technical challenges, previous investigators have demonstrated a reduction of cardiopulmonary bypass and aortic crossclamp times during mitral valve repair, as well as a reduction of residual or recurrent mitral regurgitation using preoperative 3-dimensional transesophageal echocardiogram-based determination of chordae length. ${ }^{12}$ In the current issue, Yoshida and colleagues ${ }^{13}$ report on a novel preoperative method using computed tomography. In contrast to Carpentier's reference point method, Yoshida and colleagues ${ }^{13}$ used a computed tomography-based measurement of the distance between the papillary muscle and the free edge of the nonprolapsing leaflet opposing the prolapsing area. The authors measured an artificial chordae length of $34 \mathrm{~mm}$, which is considerably longer than reported in other studies using intraoperative measurements. ${ }^{14,15}$ 


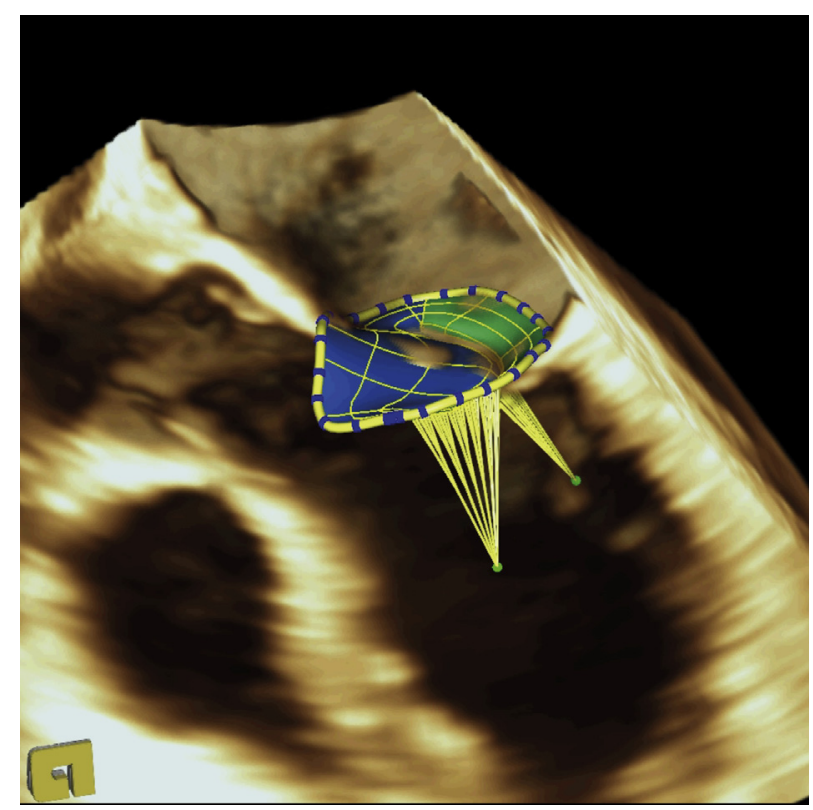

FIGURE 1. Semiautomated 3-dimensional transesophageal echocardiography-based mitral valve modeling with detection of papillary muscles. The model, currently in clinical testing, allows a model-based quantification of different distances between papillary muscles, the mitral annulus, and the leaflet edges throughout the cardiac cycle.

The precise reason for this discrepancy is unknown and requires further investigation.

With new imaging techniques, a robust and reproducible algorithm for the preoperative determination of artificial chordae length could be possible in the near future (Figure 1). ${ }^{12,13,16}$ The combination of preoperative determination and intraoperative correlation of artificial chordae length could significantly improve mitral valve repair surgery.

\section{References}

1. Frater RW, Gabbay S, Shore D, Factor S, Strom J. Reproducible replacement of elongated or ruptured mitral valve chordae. Ann Thorac Surg. 1983;35:14-28.

2. Frater RW, Vetter HO, Zussa C, Dahm M. Chordal replacement in mitral valve repair. Circulation. 1990;82:IV125-30.

3. David TE, Omran A, Armstrong S, Sun Z, Ivanov J. Long-term results of mitral valve repair for myxomatous disease with and without chordal replacement with expanded polytetrafluoroethylene sutures. J Thorac Cardiovasc Surg. 1998;115: 1279-85; discussion 1285.

4. Carpentier A, Adams DH, Filsoufi F. Carpentier's reconstructive valve surgery. From valve analysis to valve reconstruction. Maryland Heights: Saunders Elsevier; 2010.

5. Adams DH, Kadner A, Chen RH. Artificial mitral valve chordae replacement made simple. Ann Thorac Surg. 2001;71:1377-8; discussion 1378-9.

6. Kobayashi J, Sasako Y, Bando K, Minatoya K, Niwaya K, Kitamura S. Ten-year experience of chordal replacement with expanded polytetrafluoroethylene in mitral valve repair. Circulation. 2000;102:III30-4.

7. Perier P, Stumpf J, Gotz C, Lakew F, Schneider A, Clausnizer B, et al. Valve repair for mitral regurgitation caused by isolated prolapse of the posterior leaflet. Ann Thorac Surg. 1997;64:445-50.

8. von Oppell UO, Mohr FW. Chordal replacement for both minimally invasive and conventional mitral valve surgery using premeasured Gore-Tex loops. Ann Thorac Surg. 2000;70:2166-8.

9. Carpentier A. Cardiac valve surgery-the "French correction". J Thorac Cardiovasc Surg. 1983;86:323-37.

10. Frater RW. Chordae: 1959-2009. In: Hetzer R, Yankah CA, Scott Rankin J, eds. Mitral valve repair. New York: Springer-Verlag; 2011:95-110.

11. Chen X, Sun D, Yang J, Feng W, Gu T, Zhang Z, et al. Preoperative assessment of mitral valve prolapse and chordae rupture using real time threedimensional transesophageal echocardiography. Echocardiography. 2011;28: 1003-10.

12. Huang HL, Xie XJ, Fei HW, Xiao XJ, Liu J, Zhuang J, et al. Real-time threedimensional transesophageal echocardiography to predict artificial chordae length for mitral valve repair. J Cardiothorac Surg. 2013;8:137.

13. Yoshida S, Toda K, Miyagawa S, Yoshikawa Y, Sawa Y. Preoperative determination of artificial chordae length with 320-slice computed tomographic images. $J$ Thorac Cardiovasc Surg. 2017;154:1634-7.

14. Kuntze T, Borger MA, Falk V, Seeburger J, Girdauskas E, Doll N, et al. Early and mid-term results of mitral valve repair using premeasured Gore-Tex loops ('loop technique'). Eur J Cardiothorac Surg. 2008;33:566-72.

15. Merk DR, Mohr FW, Seeburger J. Mitral valve repair with neo-chordae. Ann Car diothorac Surg. 2015;4:291-2.

16. Noack T, Mukherjee C, Kiefer P, Emrich F, Vollroth M, Ionasec RI, et al. Fourdimensional modelling of the mitral valve by real-time 3D transoesophageal echocardiography: proof of concept. Interact Cardiovasc Thorac Surg. 2015; 20:200-8. 